Check for updates

Cite this: RSC Adv., 2018, 8, 35083

\title{
Nitrogen-doped micro-nano carbon spheres with multi-scale pore structure obtained from interpenetrating polymer networks for electrochemical capacitors $\uparrow$
}

\author{
Bing $\mathrm{Hu},{ }^{a}$ Wei-Bin Zhang, ${ }^{a}$ Kun Yan, ${ }^{a}$ Tong Zhang, ${ }^{a}$ Kai Li, ${ }^{a}$ Xi-Wen Chen, ${ }^{a}$ Long Kang ${ }^{b}$ \\ and Ling-Bin Kong (D) *ab
}

A chemical process was developed to prepare $\mathrm{N}$-doped micro-nano carbon spheres with multi-scale pore structures via carbonization of N-PF/PMMA interpenetrating polymer networks, which contain melamine resin as the nitrogen source, PF as the carbon source, and polymethylmethacrylate (PMMA) as the pore-former. The $\mathrm{N}$-content of $\mathrm{N}$-doped micro-nano carbon spheres was controlled by adjusting the mass ratio of melamine and phenol before polymerization. The $\mathrm{N}$-doped micro-nano carbon spheres as electrode materials possess appropriate pore size distribution, higher specific surface area (559 $\mathrm{m}^{2} \mathrm{~g}^{-1}$ ) and consistently dispersed nitrogen atoms with adjustable doping content. These distinct characteristics endow the prospective electrode materials with excellent performance in electrochemical capacitors. In particular, N-CSIPN-4 exhibits the highest specific capacitance of $364 \mathrm{~F} \mathrm{~g}^{-1}$ at $0.5 \mathrm{~A} \mathrm{~g}^{-1}$ in $6 \mathrm{M} \mathrm{KOH}$ aqueous electrolyte in a three-electrode system. It also possesses superior rate capability $(57.7 \%$ retention at current densities ranging from 0.5 to $50 \mathrm{~A} \mathrm{~g}^{-1}$ ) and excellent cycling performance at $2 \mathrm{~A} \mathrm{~g}^{-1}$ (100\% retention after 10000 cycles). All these results confirm that the $\mathrm{N}$-doped micro-nano carbon spheres are promising electrochemical capacitor materials, which possesses the advantages of simple preparation procedure, multi-scale pore structures, higher specific surface areas, easy adjustment of $\mathrm{N}$-content and excellent electrochemical properties.

Received 9th July 2018 Accepted 24th September 2018

DOI: $10.1039 / c 8 r a 05851 b$

rsc.li/rsc-advances cycling life due to their poor conductivity and instability. In contrast, introducing heteroatoms can enhance the performance of carbon-based electrode materials and maintain the superior intrinsic features of carbon-based materials. ${ }^{12-14}$ On the one hand, the primary method for the introduction of heteroatoms into carbon-based materials is the post-treatment approach. In this approach, $\mathrm{N}$-containing chemicals (e.g., ammonia and urea) can be treated with preformed carbon-based materials such as graphenes, activated carbon, and templated carbon. ${ }^{15,16} \mathrm{Li}$ et al. fabricated $\mathrm{N}$ doped graphene by employing annealing treatment of graphene oxide in ammonia, which can enhance the conductivity and specific capacitance of $\mathrm{N}$-doped graphene. ${ }^{17}$ Nevertheless, it is difficult to fabricate stable $\mathrm{N}$-doped graphene with uniform dispersion and controlled N-doping using this method. ${ }^{18}$ On the other hand, for fabricating more uniform dispersions of heteroatoms in carbon-based materials, in situ synthesis approach has been developed. In this method, N-containing polymer were used, such as poly(acrylonitrile), melamine, and polyaniline. ${ }^{19-21} \mathrm{Li}$ et al. fabricated N-doped mesoporous carbon with excellent electrochemical properties. ${ }^{12}$ This N-doped mesoporous carbon, synthesized from the melamine resins, possesses specific capacitance of $289 \mathrm{~F} \mathrm{~g}^{-1}$ at $0.2 \mathrm{~A} \mathrm{~g}^{-1}$. Furthermore, Lee et al. fabricated monodispersed N-doped carbon nanospheres by pyrolysis of polymer spheres made of polystyrene and melamine. ${ }^{22}$ These
${ }^{a}$ State Key Laboratory of Advanced Processing and Recycling of Non-ferrous Metals, Lanzhou University of Technology, Lanzhou 730050, P. R. China. E-mail: konglb@ lut.cn; Fax: +86-931-2976578; Tel: +86-931-2976579

${ }^{b}$ School of Materials Science and Engineering, Lanzhou University of Technology, Lanzhou 730050, P. R. China

$\dagger$ Electronic supplementary information (ESI) available. See DOI: 10.1039/c8ra05851b via a transition metal oxide or by doping heteroatoms ( $\mathrm{N}$ and $\mathrm{O}) \mathbf{}^{\mathbf{1 1}}$ Transition metal oxides associated with carbon-based electrode 
monodispersed $\mathrm{N}$-doped carbon nanospheres have a specific capacitance of $191.9 \mathrm{~F} \mathrm{~g}^{-1}$ at $0.1 \mathrm{~A} \mathrm{~g}^{-1}$. However, these methods did not concretely adjust the $\mathrm{N}$ doping content, and the specific capacitance of these carbon-based materials was not quite high. Recently, investigators also fabricated a nitrogen-doped porous carbon by surface activation with $\mathrm{HNO}_{3}$ solution. ${ }^{19}$ However, this method is time-consuming and harmful for our environment.

Herein, we present a facile and effective method that involved the preparation of nitrogen-doped micro-nano carbon spheres with multi-scale pore structure by employing melamine resin as the $\mathrm{N}$ source. The N-doped micro-nano carbon spheres (N-CSIPNs) were successfully fabricated via straightforward carbonization of N-PF/PMMA interpenetrating polymer networks with different $\mathrm{N}$-content (Scheme 1). Melamine resin had been selected as the $\mathrm{N}$ source due to its high nitrogen content and amino reactivity. In addition, $\mathrm{N}$ doping content was easily controlled by adjusting the weight ratio of melamine and phenol prior to polymerization. Moreover, the low cross-linking density-PMMA network was pyrolyzed, releasing gaseous products and leaving pores on carbon spheres. In this study, we also investigated the morphology of N-doped micro-nano carbon spheres, configurations of doped nitrogen and electrochemical performance of the carbon spheres. Excellent specific capacitance of $364 \mathrm{~F} \mathrm{~g}^{-1}$ at $0.5 \mathrm{~A} \mathrm{~g}^{-1}$ was obtained by the $6.44 \% \mathrm{~N}$-doped micro-nano carbon spheres with multi-scale pore structure. In summary, the asprepared N-CS-IPNs possess potential as promising electrode materials for electrochemical capacitors with higher specific capacitance as well as superior rate performance.

\section{Experimental section}

\subsection{Synthesis of $\mathbf{N}$-doped micro-nano carbon sphere}

In a typical process (Scheme $\mathrm{S} 1 \dagger$ ), $2 \mathrm{~g}$ melamine and $0.9 \mathrm{~g}$ phenol were added to into a three-neck flask and melted at $45{ }^{\circ} \mathrm{C}$; then,
$22.5 \mathrm{~mL}$ of $0.1 \mathrm{M} \mathrm{NaOH}$ was added gradually following continuous stirring. Subsequently, $10 \mathrm{~mL}$ of formalin solution (37 wt\%) was added slowly. The reaction mixture was stirred at $70{ }^{\circ} \mathrm{C}$ for $3 \mathrm{~h}$. Subsequently, $150 \mathrm{~mL}$ of deionized water was added into reaction mixture, and the reaction was continued for $17 \mathrm{~h}$ under $70{ }^{\circ} \mathrm{C}$ without $\mathrm{N}_{2}$ safeguard. The obtained dark-pink solution had been transferred into an autoclave after fixing the $\mathrm{pH}$ to 9; then the solution was heated to and maintained at $150{ }^{\circ} \mathrm{C}$ for $9 \mathrm{~h}$. The resulting material was obtained using centrifugation, washed with ethanol and dried in a freeze-drying facility. The final product was used as the N-PF polymer (I) network for subsequent preparation of IPN.

For the preparation of N-PF/PMMA-IPNs (Scheme S2 $\dagger$ ), the $\mathrm{N}-\mathrm{PF}$ polymer (I) was treated with the monomer methyl methacrylate (MMA) (II) in the presence of a crosslinking agent ethylene glycol dimethacrylate (EGDMA, 3\% by weight with respect to MMA) and an initiator 2,2-azobisisobutyronitrile (AIBN, $0.5 \%$ by weight with respect to MMA). The second monomer (MMA) mixture was allowed to polymerize and crosslink in situ in $30 \mathrm{~g}$ of $N, N$-dimethylformamide (DMF) in a $100 \mathrm{~mL}$ three-necked flask. Then, this compound was stirred, purged with nitrogen for $1 \mathrm{~h}$ and polymerized at $80{ }^{\circ} \mathrm{C}$ for $6 \mathrm{~h}$. The as-obtained sample was transferred to a ceramic plate, followed by evaporation of the solvent at $120{ }^{\circ} \mathrm{C}$ for $6 \mathrm{~h}$ in a drying oven. The final product was an interpenetrating polymer network of N-PF/PMMA (N-PF/PMMA-IPNs).

The N-PF/PMMA-IPNs were ground into a fine powder. $\mathrm{N}$ CS-IPNs were prepared by carbonizing the N-PF/PMMA-IPNS powder at $700{ }^{\circ} \mathrm{C}$ under nitrogen atmosphere for $2 \mathrm{~h}$ at a heating rate of $2{ }^{\circ} \mathrm{C} \mathrm{min}^{-1}$. The as-obtained carbon was named as N-CS-IPN-2. For the preparation of N-CS-IPN-3 and $\mathrm{N}-\mathrm{CS}$-IPN-4, the amounts of melamine used were $3 \mathrm{~g}$ and $4 \mathrm{~g}$, respectively. The other parameters were the same as those for the preparation of N-CS-IPN-2.

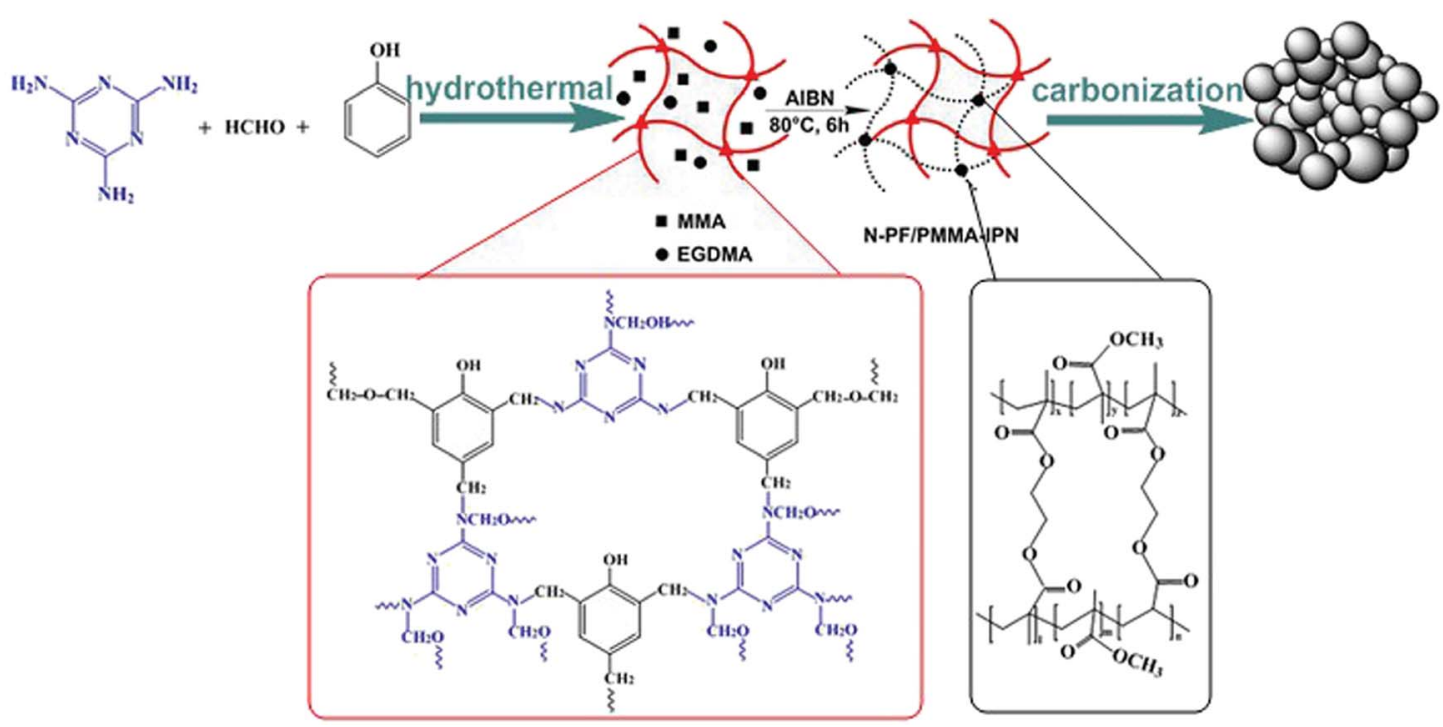

Scheme 1 Schematic of the preparation procedure for micro-nano carbon spheres with multi-scale pore structures obtained from interpenetrating polymer networks. 


\subsection{Characterization}

Fourier transform infrared (FTIR) spectra were measured using a Bruker Equinox 55 FTIR spectrophotometer. The specimens were prepared using casting pellets from sample/KBr compound. TGA and DSC were measured under $\mathrm{N}_{2}$ flow with a heating rate of $10{ }^{\circ} \mathrm{C} \mathrm{min}^{-1}$. Morphologies and structures of the samples were obtained using scanning electron microscopy (SEM) and transmission electron microscopy (TEM, $200 \mathrm{kV}$ ). Raman spectra were obtained by a Renishaw inVia spectrometer with a $520 \mathrm{~nm}$ Ar-ion laser. Powder X-ray Diffraction (XRD) patterns were measured on a Bruker Focus D8 diffractometer with $\mathrm{Cu} \mathrm{K} \alpha$ radiation $\left(40 \mathrm{kV}, \lambda=0.15418 \mathrm{~nm}\right.$ ) between $10^{\circ}$ and $90^{\circ}$. Pore structure was determined using a Micromeritics ASAP 2020 surface area and porosity analyzer. Specific surface areas were analyzed by Brunauer-Emmett-Teller (BET) theory. Pore size distribution (PSD) was calculated according to the nonlocal density functional theory (NLDFT). Total pore volumes were calculated from the amount adsorbed at a relative pressure $\left(P / P_{0}\right)$ of 0.99 . X-ray photoelectron spectroscopy (XPS) data were collected using a Sigma probe (Thermo VG Scientific) for analyzing the chemical structures of N-CS-IPNs.

\subsection{Electrochemical measurements}

N-CS-IPN electrodes were prepared by mixing electroactive material powder (80 wt\%), conductive graphite (7.5 wt\%), acetylene black (7.5 wt\%) and polytetrafluorethylene (PTFE, $5 \mathrm{wt} \%$ dispersion in water) in ethanol. Then, the compound was pressed onto a nickel foam current collector (surface area: $1 \mathrm{~cm}$ $\times 1 \mathrm{~cm}$ ). The mass of electroactive material powder in each electrode is about $4 \mathrm{mg}$. The treated nickel foam was pressed under $10 \mathrm{MPa}$ and dried at $110{ }^{\circ} \mathrm{C}$ for $12 \mathrm{~h}$ in a drying oven.

In a normative three-electrode system, the EDLC properties were measured in $6 \mathrm{M} \mathrm{KOH}$ electrolyte using an electrochemical working station (CHI660E, Shanghai, China) with a platinum foil counter electrode, saturated calomel reference electrode (SCE), and the as-prepared N-CS-IPN working electrode. Cyclic voltammetry (CV) was performed under different scan rates, and galvanostatic charge-discharge (GCD) profiles were obtained under various current densities. Specific capacitances $\left(C_{\mathrm{m}}\right)$ were calculated according to the equation $C_{\mathrm{m}}=C / m=I \times$ $\Delta t /(m \times \Delta V)$, where $C_{\mathrm{m}}\left(\mathrm{F} \mathrm{g}^{-1}\right), m(\mathrm{~g}), I(\mathrm{~A}), \Delta t(\mathrm{~s})$, and $\Delta V(\mathrm{~V})$ signify the specific capacitance, the mass of carbon-based working electrodes, the constant current density, discharging time and discharge potential, respectively. Electrochemical impedance spectroscopy (EIS) measurement was performed in frequencies ranging from $10^{5}$ to $10^{-2} \mathrm{~Hz}$ under open circuit potential with an AC perturbation of $5 \mathrm{mV}$.

For a two-electrode system, two N-CS-IPN-4 electrodes containing $8 \mathrm{mg}$ electroactive material were constructed into a symmetric capacitor. Specific capacitance $\left(C_{\mathrm{m}}, \mathrm{F} \mathrm{g}^{-1}\right)$ of the electrode material, specific power $\left(P, \mathrm{~kW} \mathrm{~kg}^{-1}\right)$ and specific energy $\left(E, \mathrm{~W} \mathrm{~h} \mathrm{~kg}{ }^{-1}\right)$ of the capacitor were calculated from the discharge curves using the following relationships: $E=C_{\mathrm{m}} \times$ $\Delta^{2} V / 2 \times 1000 / 3600 ; P=E / \Delta t \times 3600$, where $C_{\mathrm{m}}\left(\mathrm{F} \mathrm{g} \mathrm{g}^{-1}\right), \Delta V(\mathrm{~V})$, $\Delta t(\mathrm{~s})$, and $m(\mathrm{~g})$ represent specific capacitance, change in discharge potential, discharge time and mass of carbon-based material used in the two working electrode, respectively.

\section{Results and discussion}

The fabrication of nitrogen-doped micro-nano carbon spheres is illustrated in Scheme 1. First, N-PF, which was the (I) polymer network, was prepared, as shown in Scheme S1. $\dagger^{\mathbf{1 1}}$ Subsequently, the N-PF polymer (I) was treated with MMA (II) monomers using a crosslinking agent EGDMA and an initiator AIBN, and the second monomer (MMA) mixture was allowed to polymerize and crosslink in situ (Scheme S2 $\dagger$ ). ${ }^{51}$

As shown in Fig. 1, the thermal stability of the as-prepared materials was monitored by TGA. The microphase-separation of polymers is usually studied by DSC. ${ }^{23,24}$ The weight loss stages of N-PF/PMMA interpenetrating polymer networks are clearly observed during the heating course, indicating the existence of three distinct stages in the TGA curves. ${ }^{25,26}$ The first mass loss stage is observed because the nanonetwork structure of N-PF undergoes sintering and partial dehydrogenation, which agrees with the exothermic peak at $150-280{ }^{\circ} \mathrm{C}$. The second stage occurs in the temperature range of $300-430{ }^{\circ} \mathrm{C}$ due to the decomposition of PMMA networks. In fact, the PMMA networks are completely decomposed at $410{ }^{\circ} \mathrm{C}$ due to the low cross-linking density (Fig. S1†). The third mass loss stage is observed at $440-700{ }^{\circ} \mathrm{C}$, which is associated with the complete carbonization of N-PF for transformation into a local graphitic structure. ${ }^{27,28}$ Furthermore, the char yields of N-PF/PMMA-IPN2, N-PF/PMMA-IPN-3, and N-PF/PMMA-IPN-4 are $10.83 \mathrm{wt} \%$, $17.56 \mathrm{wt} \%$, and $17.30 \mathrm{wt} \%$ at $700{ }^{\circ} \mathrm{C}$, respectively. Two melting transitions are obtained from the DSC curves, which indicate two glass transition temperatures $\left(T_{\mathrm{g}}\right)$ for the three samples.
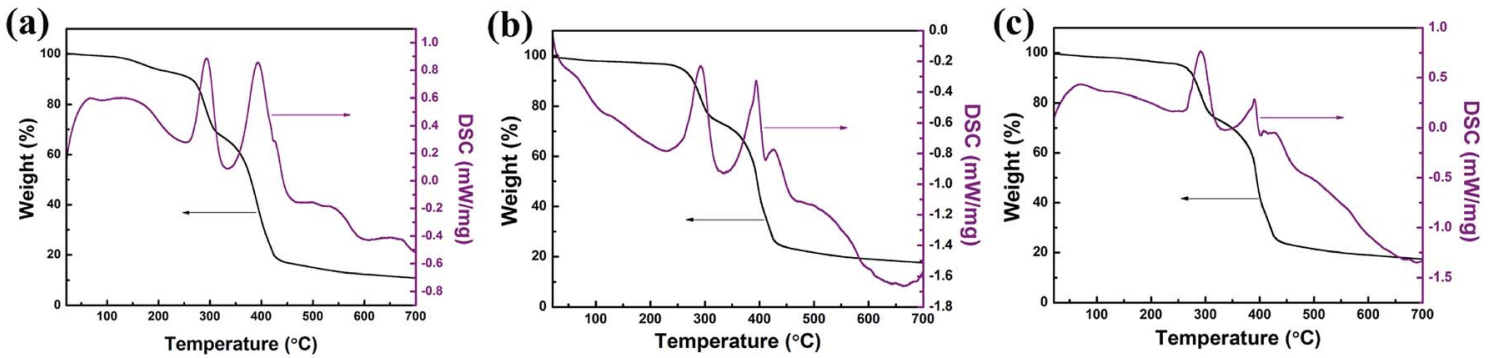

Fig. 1 TGA and DSC curves of (a) N-PF/PMMA-IPN-2, (b) N-PF/PMMA-IPN-3, and (c) N-PF/PMMA-IPN-4. 

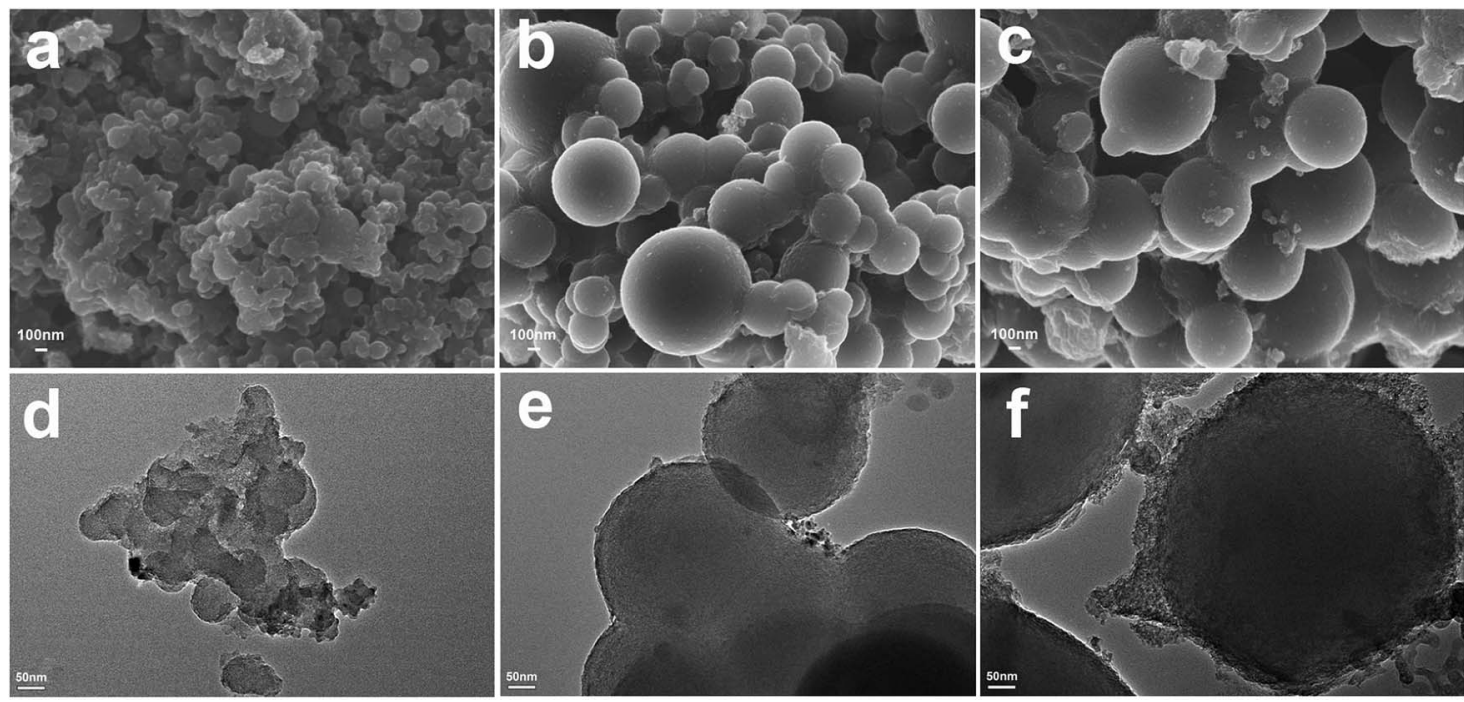

Fig. 2 SEM images of (a) N-CS-IPN-2, (b) N-CS-IPN-3, and (c) N-CS-IPN-4. TEM images of (d) N-CS-IPN-2, (e) N-CS-IPN-3, and (f) N-CS-IPN-4.

The two $T_{\mathrm{g}}$ of N-PF/PMMA-IPN-2, N-PF/PMMA-IPN-3, and N-PF/ PMMA-IPN-4 are $292.88{ }^{\circ} \mathrm{C}$ and $393.91{ }^{\circ} \mathrm{C}, 291.81{ }^{\circ} \mathrm{C}$ and $394.80{ }^{\circ} \mathrm{C}$, and $291.44{ }^{\circ} \mathrm{C}$ and $390.30{ }^{\circ} \mathrm{C}$, respectively. The existence of two melting transitions indeed implies the microphaseseparation in the N-PF/PMMA interpenetrating polymer networks. ${ }^{27,29}$

Nanostructure morphologies of N-CS-IPN-2, N-CS-IPN-3, and N-CS-IPN-4 were observed by SEM and TEM (Fig. 2). The SEM photographs (Fig. 2a-c) indicate that all the carbon materials are composed of micro-nano carbon spheres. The spherical shapes of N-CS-IPN-3 and N-CS-IPN-4 are better than those of NCS-IPN-2. We find that the size of carbon spheres increased following the increase in mass of melamine (nitrogen source). The TEM images (Fig. 2e and f) of N-CS-IPNs also demonstrate the carbon spheres with increasing order of diameter. Each unit of the $\mathrm{N}$-doped carbon spheres has micropores, and the decomposition of PMMA leaves pores in carbon spheres in the form of mesopores. In addition, the high resolution transmission electronic microscopy (HRTEM) image also shows partial graphitic structure, which results in an enhanced electrical conductivity (Fig. S2 $\dagger$ ). Electron diffraction diagrams of the three samples, shown as insets in Fig. S2 $\dagger$, indicate that the carbon samples are approximately crystalline.

As can be seen in Fig. 3a, the chemical composition of the asprepared samples was characterized using FTIR. In the FTIR spectrum of the carbon sphere before calcination (N-PF/PMMAIPN), several carbon functional groups, such as $\mathrm{C}-\mathrm{OH}$ $\left(1270 \mathrm{~cm}^{-1}\right)$ and $\mathrm{C}-\mathrm{H}\left(1060 \mathrm{~cm}^{-1}\right)$, are observed, while nitrogenbased functional groups of $\mathrm{N}-\mathrm{H}\left(1342 \mathrm{~cm}^{-1}\right.$ and $\left.1469 \mathrm{~cm}^{-1}\right)$ and $\mathrm{C}=\mathrm{N}\left(1566 \mathrm{~cm}^{-1}\right)$ are also found. In addition, the
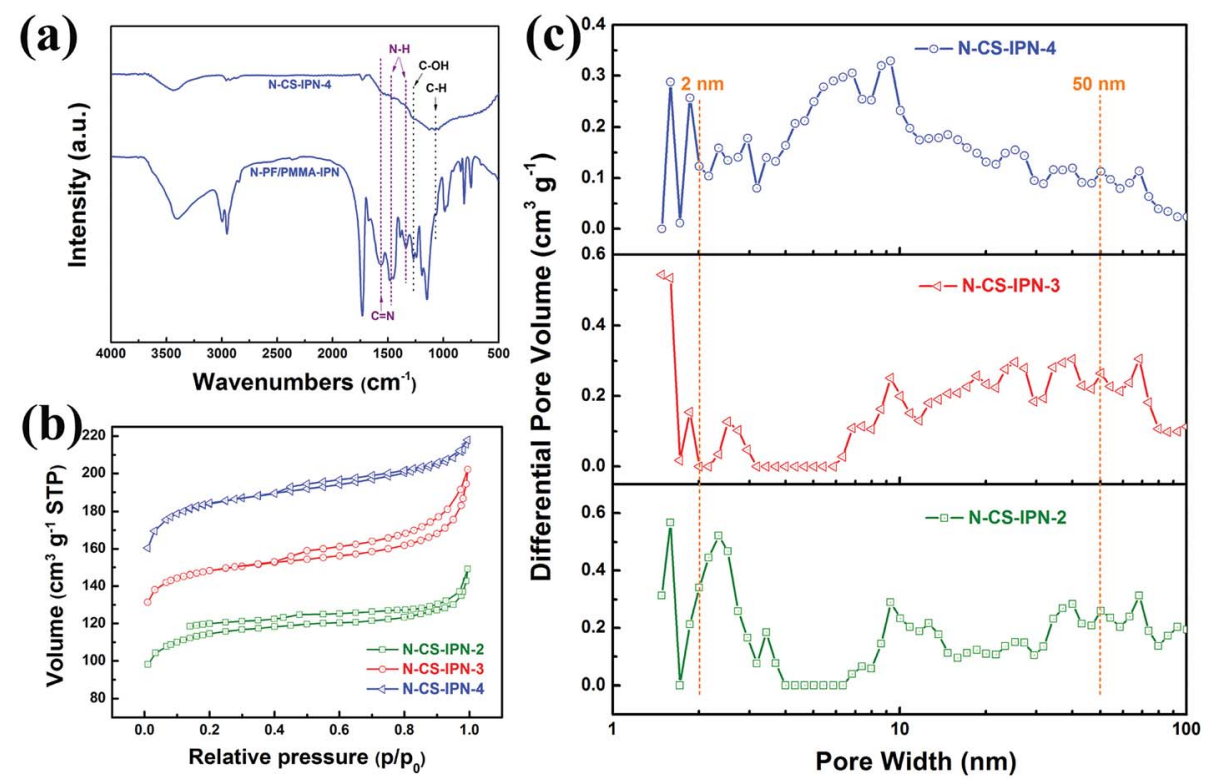

Fig. 3 (a) FTIR spectra of N-PF/PMMA-IPN and N-CS-IPN-4. (b) Nitrogen absorption-desorption isotherms of N-CS-IPN-2, N-CS-IPN-3 and NCS-IPN-4. (c) Pore size distributions of N-CS-IPN-2, N-CS-IPN-3 and N-CS-IPN-4. 
Table 1 Pore structure parameters of samples at various synthesis conditions

\begin{tabular}{|c|c|c|c|c|c|c|c|c|c|}
\hline Sample & $\begin{array}{l}\text { N-PF/PMMA } \\
\left(\mathrm{mg} \mathrm{mg}^{-1}\right)\end{array}$ & $S_{\mathrm{BET}}{ }^{a}\left(\mathrm{~m}^{2} \mathrm{~g}^{-1}\right)$ & $S_{\text {mic }}^{b}\left(\mathrm{~m}^{2} \mathrm{~g}^{-1}\right)$ & $S_{\text {meso }}^{c}\left(\mathrm{~m}^{2} \mathrm{~g}^{-1}\right)$ & $V_{\text {total }}{ }^{d}\left(\mathrm{~cm}^{3} \mathrm{~g}^{-1}\right)$ & $V_{\text {mic }}{ }^{e}\left(\mathrm{~cm}^{3} \mathrm{~g}^{-1}\right)$ & $D_{\mathrm{a}}^{f}(\mathrm{~nm})$ & N (\%) & $C_{\mathrm{g}}{ }^{h}\left(\mathrm{Fg}^{-1}\right)$ \\
\hline N-CS-IPN-2 & $20 / 80$ & 349 & 280 & 69 & 0.22 & 0.13 & 2.3 & 3.98 & 189 \\
\hline N-CS-IPN-4 & $20 / 80$ & 559 & 445 & 114 & 0.33 & 0.23 & 2.6 & 6.44 & 364 \\
\hline
\end{tabular}

${ }^{a}$ Specific surface areas were estimated by BET approach. ${ }^{b}$ Micropores surface area. ${ }^{c}$ Mesopores surface area. ${ }^{d}$ Total pore volume measured at $P / P_{0}$ $=0.99 .{ }^{e}$ Micropore volume. ${ }^{f}$ The average pore size was estimated from adsorption isotherms according to DFT model. ${ }^{h}$ Galvanostatic capacitances estimated from discharge curves at $0.5 \mathrm{~A} \mathrm{~g}^{-1}$ in $6 \mathrm{M} \mathrm{KOH}$ solution.

functional groups of carbonyl $\left(1729 \mathrm{~cm}^{-1}\right)$, ester $\left(1151 \mathrm{~cm}^{-1}\right.$ and $\left.1191 \mathrm{~cm}^{-1}\right)$, and carbon-carbon band of the benzene ring $\left(1660 \mathrm{~cm}^{-1}\right)$ can be observed, which indicates that PMMA has been successfully synthesized by monomer MMA polymerization in the polymer blend systems. The N-doped carbon spheres (N-CS-IPN-4) display similar FTIR spectra and absorption peaks. Hence, the presence of $\mathrm{N}$ functional groups in the final product could be confirmed by FTIR analysis.

The specific surface areas of N-CS-IPNs were determined by employing $\mathrm{N}_{2}$ adsorption-desorption technique. As clearly shown in Fig. 3b, all N-CS-IPNs possess similar type I/IV adsorption-desorption isotherms with hysteresis loops between the relative pressures $\left(P / P_{0}\right)$ of $0.4-1.0$. This indicates the existence of mesopore structures because of capillary condensation of the $\mathrm{N}_{2}$ molecules into mesopores. ${ }^{30}$ A high nitrogen uptake confirms the presence of abundant micropores within the micro-nano carbon spheres at low relative pressure. As shown in Fig. 3c, pore size distributions were calculated by employing nonlocal density functional theory (NLDFT). ${ }^{31} \mathrm{~N}-\mathrm{CS}$ IPNs show hierarchical porous structures as well as increased in mesopore size (such as 6.69 and $9.30 \mathrm{~nm}$ ) following the increase in N-content, which was attributed to the pyrolysis of PMMA network and the removal of heteroatoms ( $\mathrm{N}$ and $\mathrm{H}$ ) from the mesoporous surface during the carbonization process. ${ }^{19}$ Moreover, the existence of micropores of varying sizes was confirmed from the PSD curves of these carbon materials due to the removal of individual atoms $(\mathrm{C}, \mathrm{H}$, and $\mathrm{N})$; e.g., micropores with pore size in the range of 1.58-1.84 $\mathrm{nm}$. The specific surface areas $\left(S_{\mathrm{BET}}\right)$ of N-CS-IPN-2, N-CS-IPN-3, and N-CS-IPN-4 are 349, 449 , and $559 \mathrm{~m}^{2} \mathrm{~g}^{-1}$, respectively. Moreover, the total pore volumes ( $\left.V_{\text {total }}\right)$ of N-CS-IPN-2, N-CS-IPN-3, and N-CS-IPN-4 are $0.22,0.30$, and $0.33 \mathrm{~cm}^{3} \mathrm{~g}^{-1}$, respectively. The abovementioned results confirm that the interpenetrating polymer networks can successfully form nitrogen-doped micro-nano carbon spheres with multi-scale pore structures when pyrolyzed at $700{ }^{\circ} \mathrm{C}$. Table 1 illustrates the structure parameters of N-CS-IPN-2, N-CS-IPN3 , and N-CS-IPN-4, displaying the increase in $S_{\mathrm{BET}}, S_{\mathrm{mic}}$, and $V_{\text {total }}$ with the increase in nitrogen content from $3.98 \%$ to $6.44 \%$. The abovementioned results eventually lead to more effective employment of the $S_{\mathrm{BET}}$ of carbon samples.

Structural properties of N-CS-IPN-2, N-CS-IPN-3, and N-CSIPN-4 were further investigated by XRD. As shown in Fig. 4a, the (002) characteristic peak located at $23^{\circ}$ and the (100) characteristic peak located at $43^{\circ}$ were obtained in the XRD patterns of the carbon samples. The characteristic (002) peaks indicate the existence of a graphite-like microcrystalline structure generally observed for pyrolytic carbon materials. Furthermore, interlayer distances ( $0.38 \mathrm{~nm}$ ) estimated using Bragg equation are larger than those of graphite $(0.34 \mathrm{~nm}),{ }^{31}$ which indicates a random combination of graphitic and turbostratic stacking. ${ }^{32}$ The (100) characteristic peaks are attributed to the planes of amorphous carbon, indicating the formation of interlayer condensation and a mild degree of graphitic structures of the carbon materials. Structural characteristics of the as-obtained
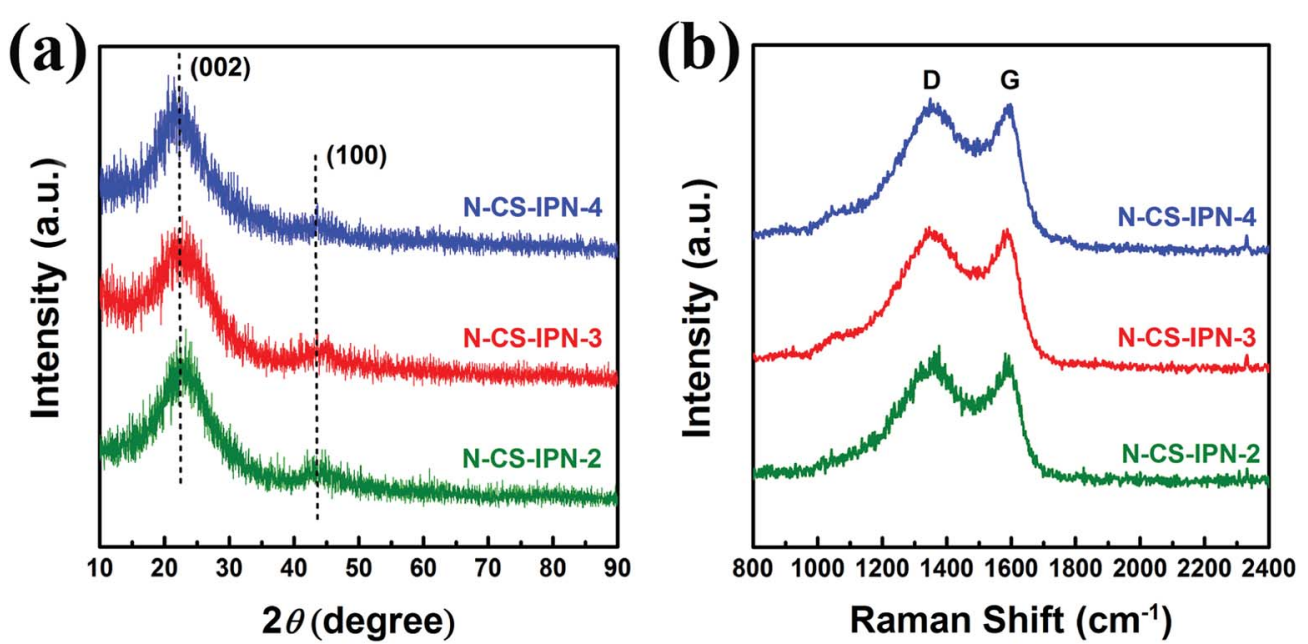

Fig. 4 (a) XRD patterns of N-CS-IPN-2, N-CS-IPN-3 and N-CS-IPN-4. (b) Raman spectra of N-CS-IPN-2, N-CS-IPN-3 and N-CS-IPN-4. 
(a)
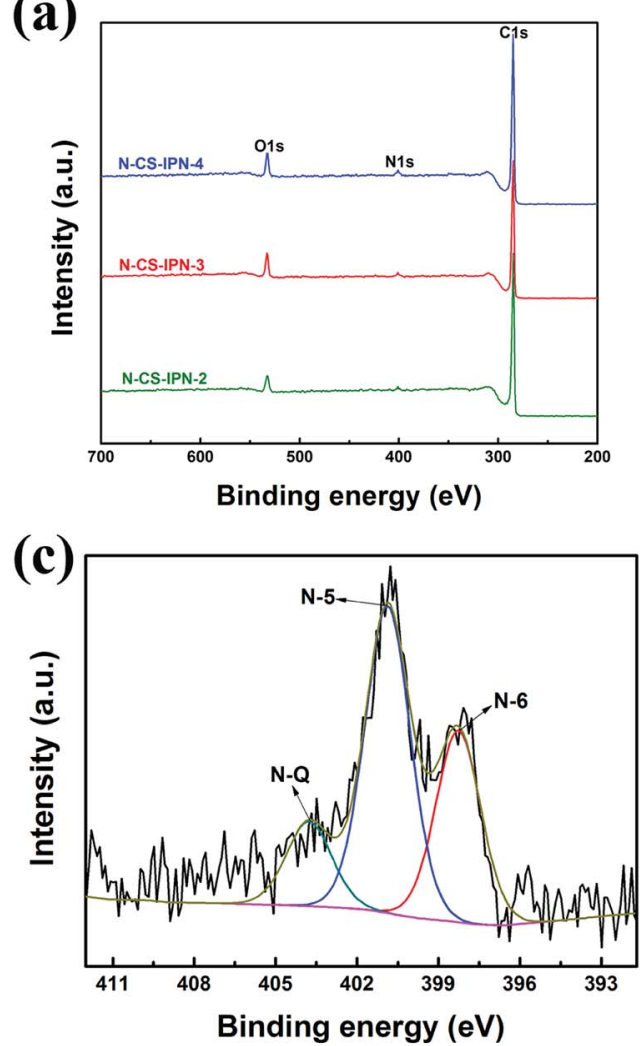

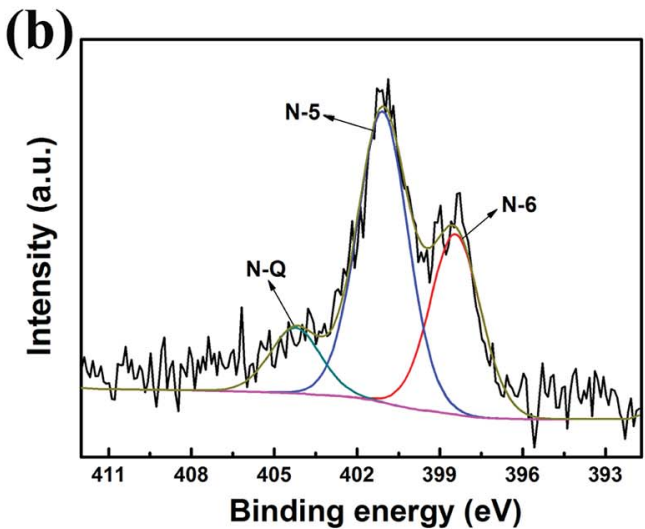

(d)

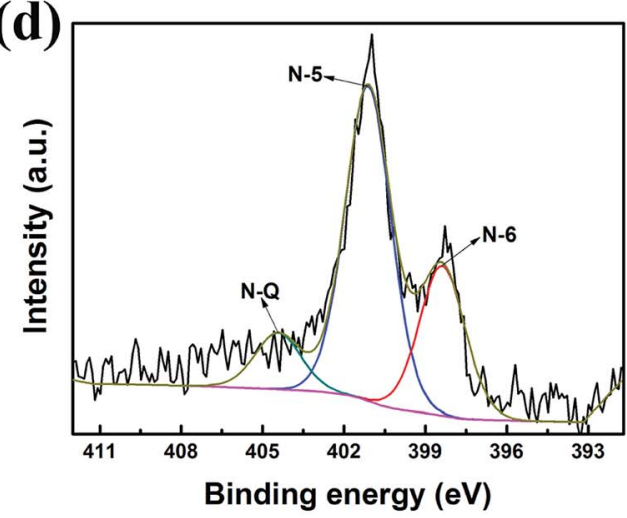

Fig. 5 (a) XPS survey spectra of N-CS-IPN-2, N-CS-IPN-3 and N-CS-IPN-4. (b) N 1s spectrum of N-CS-IPN-2, (c) N 1s spectrum of N-CS-IPN-3, (d) $\mathrm{N}$ 1s spectrum of N-CS-IPN-4.

carbon samples were further researched by recording Raman spectra. As shown in Fig. 4b, two peaks at around $1353 \mathrm{~cm}^{-1}$ and $1589 \mathrm{~cm}^{-1}$, denoted as D (disordered) peak and G (graphitic) peak, respectively, are observed for all the three samples. ${ }^{27,33}$ The D band, which is related to crystal defects, evolves due to the existence of dopant atoms and absence of graphitic carbons in N-CS-IPN materials. ${ }^{34}$ The G band, which is attributed to atomic vibrations of large graphite crystallites, ${ }^{35}$ corresponds to the presence of graphitic carbon structures in $\mathrm{N}$ CS-IPNs. It is well-known that the $I_{\mathrm{D}} / I_{\mathrm{G}}$ ratio indicates the degree of graphitization or defect density in carbon materials, and the higher value of $I_{\mathrm{D}} / I_{\mathrm{G}}$ indicates more disordered carbon structures or enhanced graphitization degree of amorphous carbon. ${ }^{36-38}$ In case of N-CS-IPNs materials, the value of $I_{\mathrm{D}} / I_{\mathrm{G}}$ increases from 1.55 to 1.69 (Table $\mathrm{S} 1 \dagger$ ) with an increase in $\mathrm{N}$ content from 2 to 4 , which indicates an increase in graphitization degree of the amorphous carbon. ${ }^{36}$ It is generally known that graphitization of carbon cloud improve electronic conductivity, whereas the type and content of doped heteroatoms are important in creating active catalytic sites in the carbon materials. ${ }^{39,40}$ The crystallite size $\left(L_{\mathrm{a}}\right)$ of N-CS-IPNs can be calculated by employing the empirical formula $L_{\mathrm{a}}=4.35 I_{\mathrm{G}} / I_{\mathrm{D}}$ (nm). $L_{\mathrm{a}}$ of N-CS-IPN-2, N-CS-IPN-3, and N-CS-IPN-4 are 2.79, 2.71, and $2.56 \mathrm{~nm}$ (Table $\mathrm{S} 1 \dagger$ ), respectively, indicating that the carbon materials possess a graphite-like microcrystalline structure.

To investigate $\mathrm{N}$ bonding configurations and $\mathrm{N}$ doping degree, XPS measurements were performed for the N-doped carbon materials. Fig. 5a clearly displays the presence of carbon, nitrogen, and oxygen elements, indicating the incorporation of nitrogen atom within the precursor. Moreover, the $\mathrm{N}$ atomic percent of N-CS-IPN-2, N-CS-IPN-3, and N-CS-IPN-4 is $3.98 \%, 5.02 \%$, and $6.44 \%$, respectively (Table 1). Fig. 5b-d display $\mathrm{N} 1 \mathrm{~s}$ spectra of N-CS-IPN-2, N-CS-IPN-3, and N-CS-IPN-4, which are fitted by three peaks: pyrrolic/pyridine $\mathrm{N}(\mathrm{N}-5,401$ $\mathrm{eV}$ ), pyridinic $\mathrm{N}(\mathrm{N}-6,398 \mathrm{eV})$ bonded to two $\mathrm{C}$ atoms of a sixmembered ring located at the edge of a graphene plane, and a quaternary nitrogen (N-Q, $404 \mathrm{eV}$ ) bonded to three $\mathrm{C}$ atoms located at the center or valley of a graphene plane. ${ }^{39-42}$ Table 2 compares the relative amounts of $\mathrm{N}$ bonding configurations for N-CS-IPN-2, N-CS-IPN-3, and N-CS-IPN-4. N-CS-IPNs exhibit a relatively large content of $\mathrm{N}-6$ and $\mathrm{N}-5$ as well as a low portion of N-Q. Moreover, the N-Q and N-6 configurations are decreased, while N-5 configuration is increased. As reported previously, higher annealing temperature or longer treatment time for nitrogen doping could be beneficial to achieve N-Q configuration over the other configurations..$^{\mathbf{2 0 4 4 , 4 3}}$ In addition,

Table 2 Approximate distributions of nitrogen functional groups measured by XPS

\begin{tabular}{lccc}
\hline Functional group & $\mathrm{N}-6 / \mathrm{N}(\%)$ & $\mathrm{N}-5 /(\%)$ & $\mathrm{N}-\mathrm{Q} /(\%)$ \\
\hline B.E. $(\mathrm{eV})$ & 398 & 401 & 404 \\
N-CS-IPN-2 & 33.57 & 54.16 & 12.27 \\
N-CS-IPN-3 & 32.64 & 55.78 & 11.58 \\
N-CS-IPN-4 & 28.72 & 60.39 & 10.89
\end{tabular}


the formation N-Q configuration requires higher energy according to a theoretical analysis. ${ }^{44}$ Therefore, it is possible to find that other configurations besides $\mathrm{N}-\mathrm{Q}$ are generated with greater degree, while the doping amount of nitrogen is enhanced. According to the literature, $\mathrm{N}$ atoms located at the edge of a graphite layer (N-5, N-6) were more positive than those located at the center of a graphite layer (N-Q) $\cdot{ }^{45-47}$ Prominently, the percentage of nitrogen located at the edge in our samples of N-CS-IPN-2 (87.73\%), N-CS-IPN-3 (88.42\%), and N-CS-IPN-4 $(89.11 \%)$ are very high. It is also reported that the $\mathrm{N}-5$ and $\mathrm{N}-6$ configurations enhance pseudocapacitance and capacitance performance, while the N-Q configuration improves conductivity of the carbon samples. ${ }^{\mathbf{4 4 , 4 8}}$

Fig. 6a displays CV curves of N-CS-IPN-2, N-CS-IPN-3, and NCS-IPN-4 in $6 \mathrm{M} \mathrm{KOH}$ electrolyte at a scan rate of $5 \mathrm{mV} \mathrm{s}^{-1}$. CV curves of the three samples exhibit quasi-rectangular shapes, indicating superior double-layer capacitance behavior with good charge transport due to their reasonable PSD and large $S_{\text {BET }}$. Clearly, N-CS-IPN-4 exhibits the largest quasi-rectangular area with excellent shapes, which implies the highest specific capacitance. Fig. 6b displays galvanostatic charge-discharge curves of N-CS-IPN-2, N-CS-IPN-3, and N-CS-IPN-4 at $0.5 \mathrm{~A} \mathrm{~g}^{-1}$. The GCD curves are almost symmetric aside from partial deviations due to the presence of nitrogen in these carbon materials, which enhances their pseudocapacitance and capacitance performance as well as improves the conductivity. Specific capacitances of these carbon materials were calculated based on the discharging time of GCD curves. Distinctly, N-CS-IPN-4 possesses the longest discharging time as well as the highest specific capacitance at $0.5 \mathrm{~A} \mathrm{~g}^{-1}$, which corroborates the results obtained from CV measurements. The highest specific capacitance of N-CS-IPN-4 might be connected with the reasonable
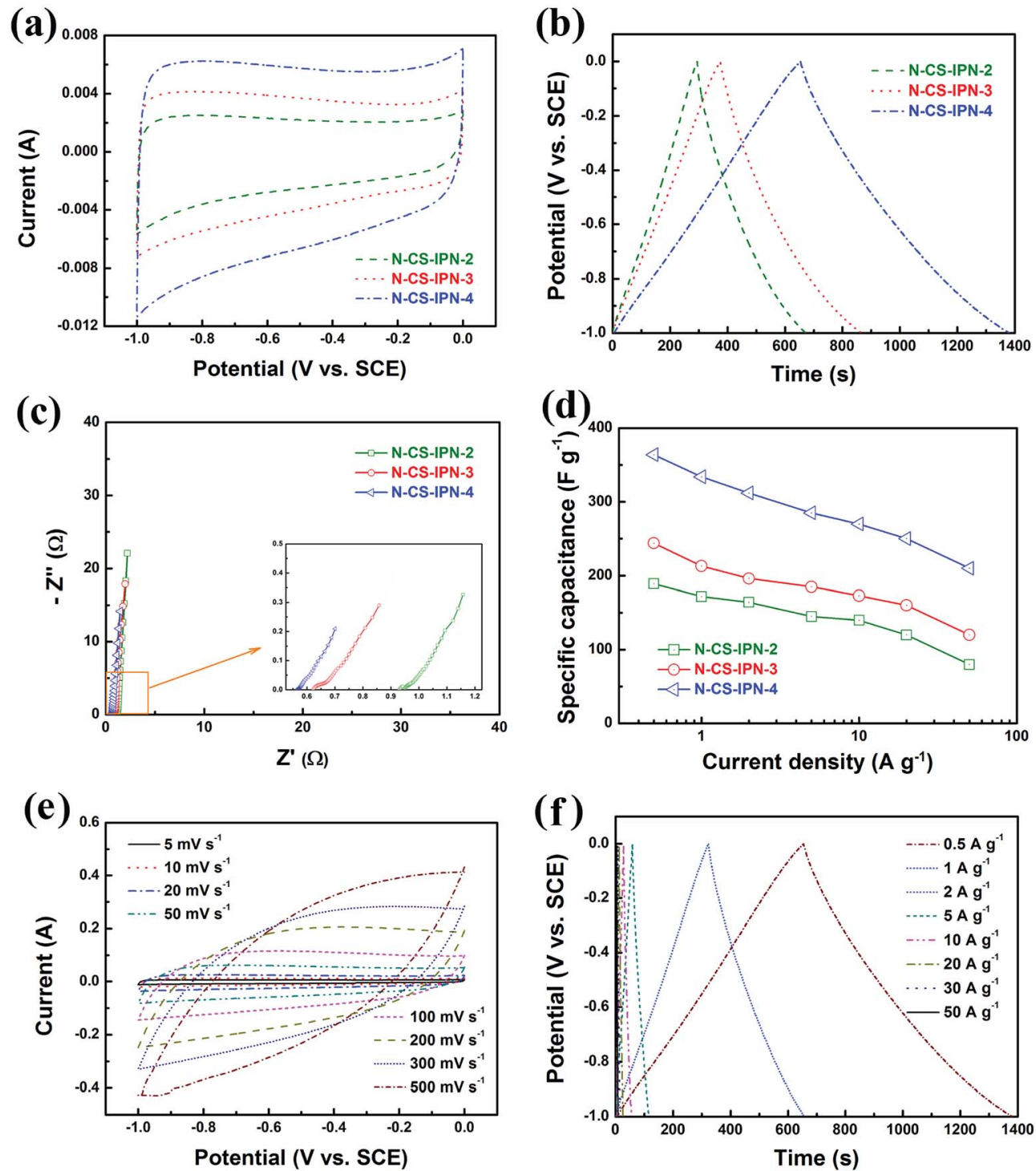

Fig. 6 (a) Cyclic voltammograms of N-CS-IPN-2, N-CS-IPN-3 and N-CS-IPN-4 at a scan rate of $5 \mathrm{mV} \mathrm{s}^{-1}$. (b) Galvanostatic charge-discharge curves of N-CS-IPN-2, N-CS-IPN-3 and N-CS-IPN-4 at a current density of $0.5 \mathrm{Ag}^{-1}$. (c) Electrochemical impedance spectra of N-CS-IPN-2, NCS-IPN-3 and N-CS-IPN-4. (d) Specific capacitances of N-CS-IPN-2, N-CS-IPN-3 and N-CS-IPN-4 at different current densities. (e) Cyclic voltammograms of N-CS-IPN-4 at different scan rates. (f) Galvanostatic charge-discharge curves of N-CS-IPN-4 at different current densities. 
pore size distribution and the highest surface area, which are in favour of the development of an electric double layer. Moreover, the nitrogen can undergo reversible redox reactions, which could contribute to the pseudocapacitance and improve the surface wettability. However, the absence of distinct redox peak in $\mathrm{CV}$ curves implies that the capacitance is mainly derived from the electric double layer. EIS measurements were conducted for N-CS-IPN-2, N-CS-IPN-3, and N-CS-IPN-4, as shown in Fig. 6c. The three impedance spectra are similar, exhibiting a small semicircle at high frequencies as well as an almost vertical line at low frequencies. Nevertheless, distinct deviations exist among the three EIS curves. The internal resistance $\left(R_{\mathrm{b}}\right)$ comprises intrinsic resistances of carbon electrodes and total electrolyte ionic resistance. The internal resistances of N-CSIPN-2, N-CS-IPN-3, and N-CS-IPN-4 electrodes were 0.93, 0.62, and $0.56 \Omega$, respectively. Clearly, the smaller $R_{\mathrm{b}}$ of N-CS-IPN-4 electrode than that of the others indicates that ion diffusion and electrolyte transfer into the pore channels easily occur, thus promoting the formation of the electric double layer. EIS curves of all the N-CS-IPNs electrodes possess angles larger than $45^{\circ}$, which reveal smaller Warburg impedances because of the enhanced electrolyte ions diffusion due to the hierarchical porous structures. For example, the diffusion resistance of $\mathrm{N}$ CS-IPN-4 was smaller than that of N-CS-IPN-2 and N-CS-IPN-3 electrodes because of introduction of hydrophilic $\mathrm{N}$ and $\mathrm{O}$ functional groups during the $\mathrm{N}$ doping process. Moreover, relatively larger resistances of N-CS-IPN-2 and N-CS-IPN-3 than that of N-CS-IPN-4 may be caused by relatively smaller pore sizes and specific surface areas that hinder ion transport and electrolyte penetration. Fig. $6 \mathrm{~d}$ exhibits the specific capacitances of N-CS-IPN-2, N-CS-IPN-3, and N-CS-IPN-4 at different current densities. It is distinctly seen that the specific capacitance has been largely increased with the increase in N content. The N-CSIPN-4 electrode provides larger specific capacitance $\left(364 \mathrm{~F} \mathrm{~g}^{-1}\right)$ than N-CS-IPN-2 (189 $\left.\mathrm{F} \mathrm{g}^{-1}\right)$ and N-CS-IPN-3 $\left(243 \mathrm{~F} \mathrm{~g}^{-1}\right)$ at $0.5 \mathrm{~A} \mathrm{~g}^{-1}$. Rate capabilities of N-CS-IPN-2, N-CS-IPN-3, and N-CSIPN-4 were $42.3 \%, 49.4 \%$, and $57.7 \%$, respectively, when current densities increased from 0.5 to $50 \mathrm{~A} \mathrm{~g}^{-1}$. N-CS-IPN-4 possesses $76.9 \%, 68.7 \%, 63.5 \%$, and $57.7 \%$ capacitance retention at 10 , 20, 30, and $50 \mathrm{~A} \mathrm{~g}^{-1}$, respectively. This implies low resistance and superior retention rate capability, indicating that the hierarchical porous structure offers effective electrolyte transfer into the carbon material. The abovementioned results for N-CS-IPN4 relate with better electrical conductivity and formation of porous structures. Moreover, the nitrogen-containing functional groups ( $\mathrm{N}-5$ and $\mathrm{N}-6)$ could also provide pseudocapacitance. Fig. 6e displays the CV curves of N-CS-IPN-4 at different scan rates. The CV curves of N-CS-IPN-4 possess good rectangular shapes from 5 to $100 \mathrm{mV} \mathrm{s}^{-1}$, indicating that N-CS-IPN-4 exhibits optimal double-layer capacitance behavior. Notably, the $\mathrm{CV}$ curves if N-CS-IPN-4 maintain the quasi-rectangular shape at a scan rate as high as $500 \mathrm{mV} \mathrm{s}^{-1}$, which reveals rapid electrolyte ions diffusion and electron transfer. Fig. $6 \mathrm{f}$ shows the GCD curves of N-CS-IPN-4 at different current densities. It is noteworthy that N-CS-IPN-4 still retains typical symmetric triangle shapes at current densities as large as $50 \mathrm{~A} \mathrm{~g}^{-1}$, indicating that N-CS-IPN-4 as an electrode material has excellent coulombic efficiency and perfect electric capacitive behavior. Specific capacitances were calculated to be 364 , $334,312,285,270,250,231$, and $210 \mathrm{~F} \mathrm{~g}^{-1}$ at different current densities of $0.5,1,2,5,10,20,30$, and $50 \mathrm{~A} \mathrm{~g}^{-1}$, respectively.

For further research on the electrochemical performance of $\mathrm{N}-\mathrm{CS}-\mathrm{IPN}-4$, the long-term cycling stability (10 000 cycles) of this electrode was evaluated by repeating the charge-discharge test at a current density of $2 \mathrm{~A} \mathrm{~g}^{-1}$ in $6 \mathrm{M} \mathrm{KOH}$ electrolyte. As shown as Fig. 7, N-CS-IPN-4 electrode possesses excellent cycling property with $100 \%$ specific capacitance retained after 10000 cycles, which demonstrates its good reversibility and superior cycle stability in continuous charge-discharge process. The inset is the SEM image of N-CS-IPN-4 after 10000 cycles, indicating that the carbon spheres still maintain good shape.

A symmetric two-electrode system was employed for further confirming the electrochemical properties of N-CS-IPN-4 in $6 \mathrm{M} \mathrm{KOH}$ electrolyte (Fig. 8). Fig. 8a displays the CV curves of N-CS-IPN-4//N-CS-IPN-4-based electrochemical capacitor at different scan rates, revealing a good rectangular shape at scan rates as high as $50 \mathrm{mV} \mathrm{s}^{-1}$ and suggesting that this capacitor possesses good rate capability. Fig. 8b shows triangle-like galvanostatic charge-discharge curves of N-CS-IPN-4//N-CSIPN-4, which indicates its superior reversible capacitive behavior. Moreover, this capacitor shows superior capacitance retention of $75.6 \%$ at different current densities from 0.5 to $10 \mathrm{~A} \mathrm{~g}^{-1}$. For comparison, the electrochemical properties of $\mathrm{N}$ CS-IPN-4 and AC were investigated in symmetric two-electrode systems. The CV curves of N-CS-IPN-4//N-CS-IPN-4 and AC//AC are shown in Fig. 8c, where the rectangular shape of the symmetric N-CS-IPN-4 electrode was larger than that for the symmetric AC electrode, indicating that the specific capacitance of symmetric N-CS-IPN-4 electrode was higher than that for AC. Fig. 8d displays the triangle-like galvanostatic chargedischarge curves of the two symmetric electrode systems. The N-CS-IPN-4 and AC capacitors exhibit specific capacitances of $90 \mathrm{~F} \mathrm{~g}^{-1}$ and $36 \mathrm{~F} \mathrm{~g}^{-1}$, respectively, at a current density of $0.5 \mathrm{~A} \mathrm{~g}^{-1}$, which implies that the symmetric N-CS-IPN-4

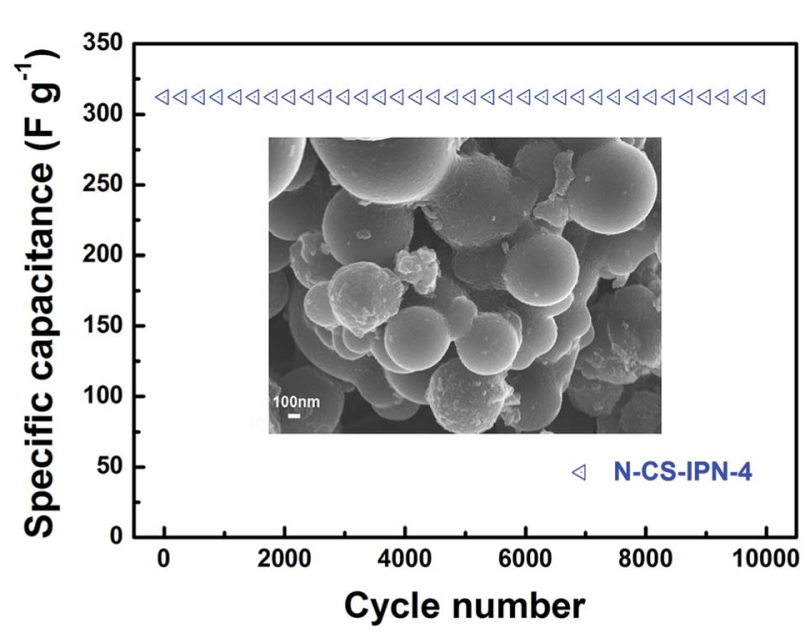

Fig. 7 Cycling performance of N-CS-IPN-4 measured at a constant current density of $2 \mathrm{~A} \mathrm{~g}^{-1}$ (inset: SEM image after 10000 cycles). 
(a)

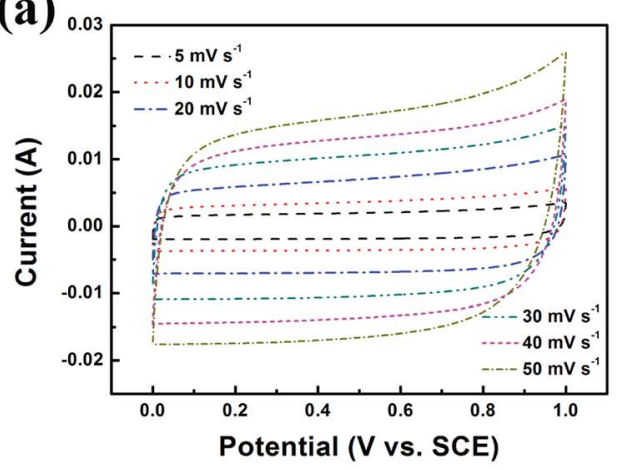

(c)

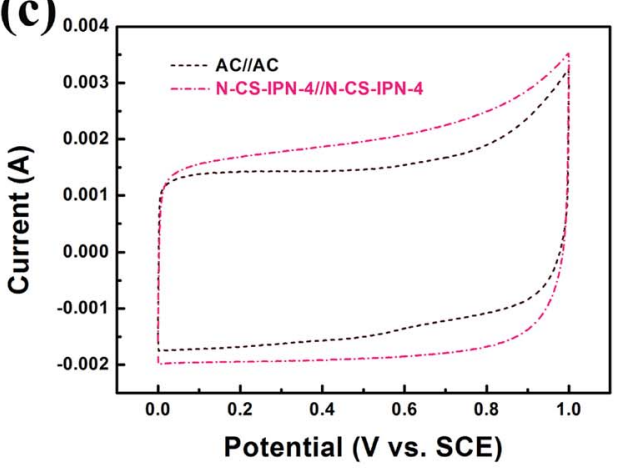

(e)

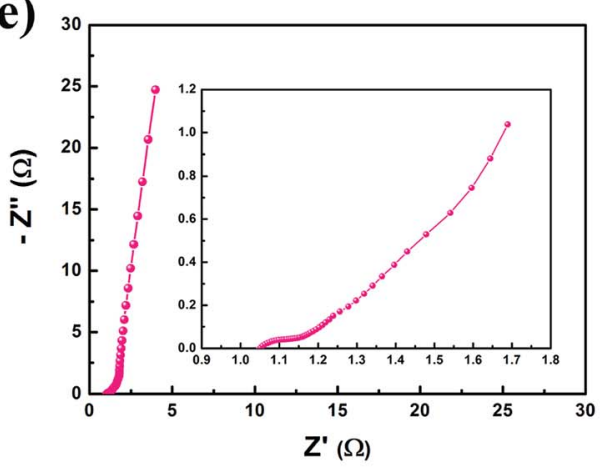

(b)

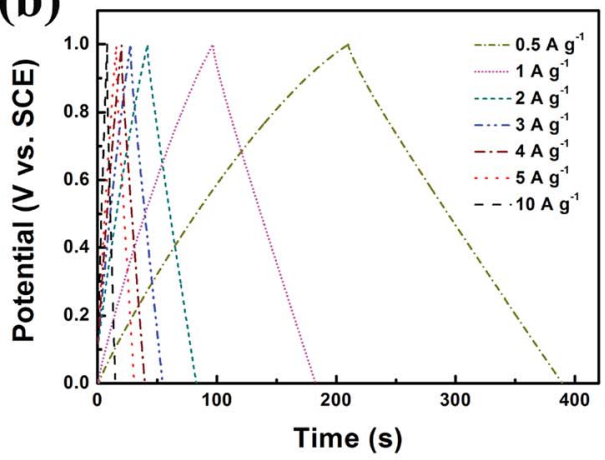

(d)

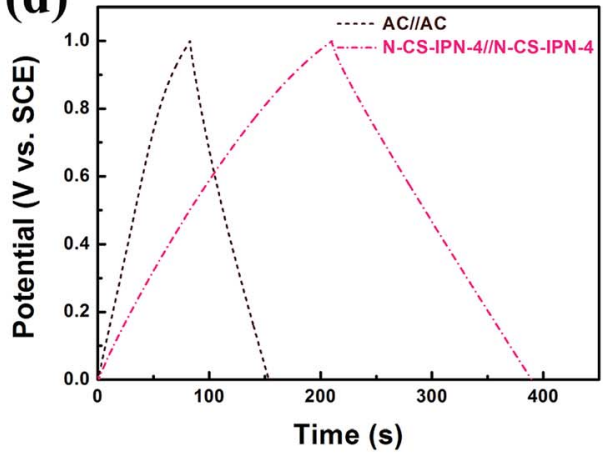

(f)

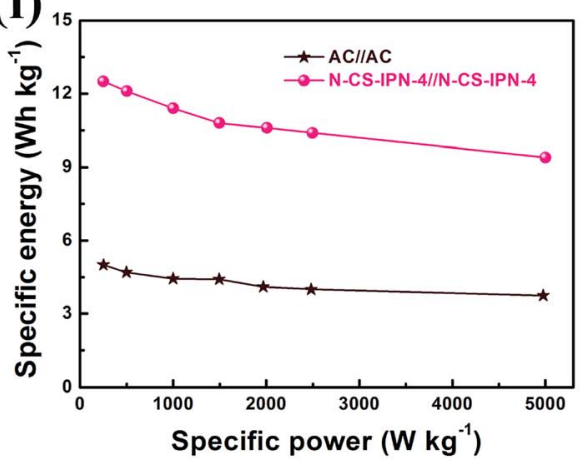

Fig. 8 (a) Cyclic voltammograms of N-CS-IPN-4//N-CS-IPN-4 at various scan rates. (b) Galvanostatic charge-discharge curves of N-CS-IPN$4 / / \mathrm{N}-\mathrm{CS}-$ IPN-4 at various current densities. (c) CVs of AC//AC and N-CS-IPN-4//N-CS-IPN-4 at a scan rate of $5 \mathrm{mV} \mathrm{s}{ }^{-1}$. (d) Charge-discharge curves of N-CS-IPN-4//N-CS-IPN-4 and AC//AC at a current density of $0.5 \mathrm{~A} \mathrm{~g}^{-1}$. (e) EIS curve of N-CS-IPN-4//N-CS-IPN-4. (f) Ragone plots of $\mathrm{N}-\mathrm{CS}-\mathrm{IPN}-4 / / \mathrm{N}-\mathrm{CS}-\mathrm{PPN}-4$ and $\mathrm{AC} / / \mathrm{AC}$ devices.

electrode possesses better electrochemical properties than AC. The EIS curve of N-CS-IPN-4//N-CS-IPN-4 is shown in Fig. 8e. A small semicircle could be observed for the N-CS-IPN-4 capacitor (Fig. 8e, inset) in the high frequency region, indicating its correspondingly smaller charge transfer resistance and better conductivity. ${ }^{49,50}$ The specific energy and specific power are key parameters to determine the electrochemical properties of electrode materials, which are estimated from the galvanostatic charge-discharge curves. The Ragone plots of N-CS-IPN4//N-CS-IPN-4 and AC//AC are displayed in Fig. 8f. The specific energy is much larger $\left(12.5 \mathrm{~W} \mathrm{~h} \mathrm{~kg}^{-1}\right)$ for N-CS-IPN-4//N-CSIPN-4 than for the AC//AC symmetric capacitor $\left(5 \mathrm{~W} \mathrm{~h} \mathrm{~kg}^{-1}\right)$ at $0.5 \mathrm{~A} \mathrm{~g}^{-1}$. In addition, the specific energy of N-CS-IPN-4//NCS-IPN-4 remained at $9.4 \mathrm{~W} \mathrm{~h} \mathrm{~kg}^{-1}$ with a high specific power of $4.98 \mathrm{~kW} \mathrm{~kg}^{-1}$ at a current density as high as $10 \mathrm{~A} \mathrm{~g}^{-1}$, which was excellent compared with that of the AC//AC symmetric capacitor. Hence, the as-prepared N-CS-IPN-4 would be a promising electrode material for highly efficient electrochemical capacitors.

\section{Conclusion}

In summary, we successfully designed a synthesis protocol for preparing nitrogen-doped micro-nano carbon spheres with multi-scale pore structure by employing melamine resin as the $\mathrm{N}$ source. The $\mathrm{N}$-doped micro-nano carbon spheres were successfully fabricated via straightforward carbonization of $\mathrm{N}$ PF/PMMA interpenetrating polymer networks with different $\mathrm{N}$ content. The as-prepared N-CS-IPNs electrode materials possess applicable pore size distribution, higher surface area, and consistently dispersed nitrogen functional groups with controlled doping content. Their particular electrochemical 
performances endow them as promising electrode materials for highly efficient electrochemical capacitors with excellent properties. On the one hand, particularly, the N-CS-IPN-4 electrode possesses higher specific surface area of $559 \mathrm{~m}^{2} \mathrm{~g}^{-1}$ and better specific capacitance of $364 \mathrm{~F} \mathrm{~g} \mathrm{~g}^{-1}$ at $0.5 \mathrm{~A} \mathrm{~g}^{-1}$ compared with other N-CS-IPNs in a three-electrode system. Moreover, N-CSIPN-4 reveals excellent rate capability $(57.7 \%$ retention at current densities ranging from 0.5 to $50 \mathrm{~A} \mathrm{~g}^{-1}$ ) and excellent cycling performance at $2 \mathrm{~A} \mathrm{~g}^{-1}(100 \%$ retention after 10000 cycles). On the other hand, the electrochemical performance of the obtained carbon electrode materials was also researched using symmetrical two-electrode systems. The N-CS-IPN-4//NCS-IPN-4 device possesses much higher specific energy density (12.5 $\mathrm{W} \mathrm{h} \mathrm{kg}^{-1}$ ) than the AC//AC symmetric capacitor $\left(5 \mathrm{~W} \mathrm{~h} \mathrm{~kg}^{-1}\right)$ at $0.5 \mathrm{~A} \mathrm{~g}^{-1}$. In conclusion, these abovementioned results confirm that $\mathrm{N}$-doped micro-nano carbon spheres with multi-scale porous structures obtained from interpenetrating polymer networks will be promising electrode materials for electrochemical capacitors.

\section{Conflicts of interest}

There are no conflicts to declare.

\section{Acknowledgements}

We gratefully acknowledge the National Natural Science Foundation of China (No. 51762031) and the Foundation for Innovation Groups of Basic Research in Gansu Province (No. 1606RJIA322).

\section{References}

1 X. Sun, G.-P. Hao, X. Lu, L. Xi, B. Liu and W. Si, J. Mater. Chem. A, 2016, 4, 10166-10173.

2 F. Béguin, V. Presser, A. Balducci and E. Frackowiak, Adv. Mater., 2014, 26, 2219-2251.

3 J. R. Miller and P. Simon, Science, 2008, 321, 651-652.

4 H. Jiang, L. Yang, C. Li, C. Yan, P. S. Lee and J. Ma, Energy Environ. Sci., 2011, 4, 1813-1819.

5 M. Huang, Y. X. Zhang, F. Li, L. L. Zhang, Z. Y. Wen and Q. Liu, J. Power Sources, 2014, 252, 98-106.

6 F. X Ma, L. Yu, C. Y. Xu and X. W. Lou, Energy Environ. Sci., 2016, 9, 862-866.

7 L. L. Zhang and X. S. Zhao, Chem. Soc. Rev., 2009, 38, 25202531.

8 K. Xie, X. Qin, Y. Wang, H. Tao, Q. Wu, L. Yang and Z. Hu, Adv. Mater., 2012, 24, 347-352.

9 J. Gamby, P. L. Taberna, P. Simon, J. F. Fauvarque and M. Chesneau, J. Power Sources, 2001, 101, 109-116.

10 E. Frackowiak, Phys. Chem. Chem. Phys., 2007, 9, 1774-1785. 11 W. Li, D. Chen, Z. Li, Y. Shi, Y. Wan, J. Huang, J. Yang, D. Zhao and Z. Jiang, Electrochem. Commun., 2007, 9, 569573.

12 O. M. Li and J. M. Xue, J. Phys. Chem. C, 2014, 118, 25072517.
13 G. Lota, B. Grzyb, H. Machnikowska, J. Machnikowski and E. Frackowiak, Chem. Phys. Lett., 2005, 404, 53-58.

14 R. J. White, M. Antonietti and M. M. Titirici, J. Mater. Chem., 2009, 19, 8645-8650.

15 D. Hulicova-Jurcakova, M. Kodama, S. Shiraishi, H. Hatori, Z. H. Zhu and G. Q. Lu, Adv. Funct. Mater., 2009, 19, 18001809.

16 H. M. Jeong, J. W. Lee, W. H. Shin, Y. J. Choi, H. J. Shin, J. K. Kang and J. W. Choi, Nano Lett., 2011, 11, 2472-2477.

17 X. Li, H. Wang, J. T. Robinson, H. Sanchez, G. Diankov and H. Dai, J. Am. Chem. Soc., 2009, 131, 15939-15944.

18 Z. Wen, X. Wang, S. Mao, Z. Bo, H. Kim, S. Cui, G. Lu, X. Feng and J. Chen, Adv. Mater., 2012, 24, 5610-5616.

19 K. Yan, L. B. Kong, K. W. Shen, Y. H. Dai, M. Shi, B. Hu, Y. C. Luo and L. Kang, Appl. Surf. Sci., 2016, 364, 850-861.

20 L. F. Chen, X. D. Zhang, H. W. Liang, M. Kong, Q. F. Guan, P. Chen, Z. Y. Wu and S. H. Yu, ACS Nano, 2012, 6, 70927102.

21 L. Li, E. Liu, J. Li, Y. Yang, H. Shen, Z. Huang, X. Xiang and W. Li, J. Power Sources, 2010, 195, 1516-1521.

22 W. H. Lee and J. H. Moon, ACS Appl. Mater. Interfaces, 2014, 6, 13968-13976.

23 R. Dattani, J. H. Bannock, Z. Fei, R. C. I. MacKenzie, A. A. Y. Guilbert, M. S. Vezie, J. Nelson, J. C. de Mello, M. Heeney, J. T. Cabral and A. J. Nedoma, J. Mater. Chem. A, 2014, 2, 14711-14719.

24 P. Willot, J. Teyssandier, W. Dujardin, J. Adisoejoso, S. DeFeyter, D. Moerman, P. Leclere, R. Lazzaroni and G. Koeckelberghs, $R S C A d v$. , 2015, 5, 8721-8726.

25 K. A. Smith, B. Stewart, K. G. Yager, J. Strzalka and R. Verduzco, J. Polym. Sci., Part B: Polym. Phys., 2014, 52, 900-906.

26 Y. Chen, H. Cui, L. Li, Z. Tian and Z. Tang, Polym. Chem., 2014, 5, 4441-4445.

27 M. J. Zhong, E. K. Kim, J. P. McGann, S. E. Chun, J. F. Whitacre, M. Jaroniec, K. Matyjaszewski and T. Kowalewski, J. Am. Chem. Soc., 2012, 134, 14846-14857.

28 C. T. Nguyen and D. P. Kim, J. Mater. Chem., 2011, 21, 1422614230.

29 K. T. Cho, S. B. Lee and J. W. Lee, J. Phys. Chem. C, 2014, 118, 9357-9367.

30 M. Thommes, K. Kaneko, A. V. Neimark, J. P. Olivier, F. Rodriguez-Reinoso, J. Rouquerol and K. S. W. Sing, Pure Appl. Chem., 2015, 87, 1051-1069.

31 K. T. Cho, S. B. Lee and J. W. Lee, J. Phys. Chem. C, 2014, 118, 9357-9367.

32 M. Sevilla and A. B. Fuertes, Carbon, 2013, 56, 155-166.

33 D. C. Wu, H. C. Dong, J. Pietrasik, E. K. Kim, C. M. Hui, M. J. Zhong, M. Jaroniec, T. Kowalewski and K. Matyjaszewski, Chem. Mater., 2011, 23, 2024-2026.

34 Y. Meng, D. Voiry, A. Goswami, X. Zou, X. Huang, M. Chhowalla, Z. Liu and T. Asefa, J. Am. Chem. Soc., 2014, 136, 13554-13557.

35 F. Xu, Z. W. Tang, S. Q. Huang, L. Y. Chen, Y. R. Liang, W. C. Mai, H. Zhong, R. W. Fu and D. C. Wu, Nat. Commun., 2015, 6, 7221-7231. 
36 G. Panomsuwan, N. Saito and T. Ishizaki, J. Mater. Chem. A, 2015, 3, 9972-9981.

37 G. Nanda, S. Goswami, K. Watanabe, T. Taniguchi and P. F. A. Alkemade, Nano Lett., 2015, 15, 4006-4012.

38 A. C. Ferrari and J. Robertson, Phys. Rev. B: Condens. Matter Mater. Phys., 2000, 61, 14095-14107.

39 S. Shrestha and W. E. Mustain, J. Electrochem. Soc., 2010, 157, B1665-B1672.

40 F. Kapteijn, J. A. Moulijn, S. Matzner and H. P. Boehm, Carbon, 1999, 37, 1143-1150.

41 F. Su, C. K. Poh, J. S. Chen, G. Xu, D. Wang, Q. Li, J. Lin and X. W. Lou, Energy Environ. Sci., 2011, 4, 717-724.

42 D. Hulicova-Jurcakova, M. Kodama, S. Shiraishi, H. Hatori, Z. H. Zhu and G. Q. Lu, Adv. Funct. Mater., 2009, 19, 18001809.

43 T. Van Khai, H. G. Na, D. S. Kwak, Y. J. Kwon, H. Ham, K. B. Shim and H. W. Kim, J. Mater. Chem., 2012, 22, 17992-18003.
44 D. W. Wang, F. Li, L. C. Yin, X. Lu, Z. G. Chen, I. R. Gentle, G. Q. Lu and H. M. Cheng, Chem.-Eur. J., 2012, 18, 53455351.

45 C. O. Ania, V. Khomenko, E. Raymundo-Piñero, J. B. Parra and F. Beguin, Adv. Funct. Mater., 2007, 17, 1828-1836.

46 E. J. Ra, E. Raymundo-Piñero, Y. H. Lee and F. Beguin, Carbon, 2009, 47, 2984-2992.

47 Z. Li, L. Zhang, B. S. Amirkhiz, X. Tan, Z. Xu, H. Wang, B. C. Olsen, C. M. B. Holt and D. Mitlin, Adv. Energy Mater., 2012, 2, 431-437.

48 X. Yang, D. Wu, X. Chen and R. Fu, J. Phys. Chem. C, 2010, 114, 8581-8586.

49 L. Yang, S. Cheng, Y. Ding, X. Zhu, Z. L. Wang and M. Liu, Nano Lett., 2011, 12, 321-325.

50 S. Biswas and L. T. Drzal, Chem. Mater., 2010, 22, 5667-5671. 51 J. Zhang, X. F. Zhong, H. B. Chen, Y. Gao and H. M. Li, Electrochim. Acta, 2014, 148, 203-210. 